\title{
TLR3 dsRNA agonist inhibits growth and invasion of HepG2.2.15 HCC cells
}

\author{
LI CHEN $^{1 *}$, YU-YIN XU ${ }^{2 *}$, JIA-MING ZHOU ${ }^{2}$, YUAN-YUAN WU ${ }^{2}$, QUN E $^{2}$ and YUAN-YUAN ZHU ${ }^{3}$ \\ ${ }^{1}$ Department of Pathology, Nantong Tumor Hospital; ${ }^{2}$ Department of Pathological Anatomy, \\ Nantong University; ${ }^{3}$ Biomics (Nantong) Co., Ltd., Nantong, P.R. China
}

Received December 21, 2011; Accepted February 21, 2012

DOI: $10.3892 /$ or.2012.1791

\begin{abstract}
Toll-like receptor 3 (TLR3) is a pattern-recognizing receptor that is involved in immune signaling and plays a crucial role in survival by being able to recognize various viral components including double-stranded RNA (dsRNA). TLR3 expression and function in cancer cells are not well understood. In this study, we investigated whether TLR3 agonist dsRNA (BM-06) can inhibit proliferation and invasion, and promote apoptosis in HepG2.2.15 cells. HepG2.2.15 cells secreting hepatitis B virus (HBV) were treated with BM-06 and poly(I:C). Western blot analysis and PCR were employed to determine pharmacodynamic changes in biomarkers relevant to TLR3 signaling. Cell proliferation, invasion and apoptosis were analyzed by CCK- 8 assay, transwell assay and flow cytometry. The expression of $\mathrm{HBsAg}$, and HBcAg was observed by immunohistochemistry. Compared with untreated cells, pharmacological NF- $\kappa \mathrm{B}$ activity of the TLR3 pathway by BM-06 (1.734-fold) or poly(I:C) (1.377-fold) was induced. By western blot analysis, we found that dsRNA induced TLR3-

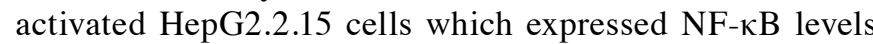
predominantly in the cytoplasmic fraction but fewer signals in the nucleus. BM-06 inhibited the proliferation, invasion and secretion of $\mathrm{HBV}$, and induced apoptosis in HepG2.2.15 cells. In addition, the antitumor effects of BM-06 were superior to poly(I:C). Pharmacological activation of the TLR3 pathway by BM-06 can inhibit HepG2.2.15 cell growth.
\end{abstract}

\section{Introduction}

Hepatocellular carcinoma (HCC) is the most common primary malignant tumor in the liver. It ranks fifth in incidence and fourth in mortality rate in tumors overall $(1,2)$. China is one of the highest prevalent areas of $\mathrm{HCC}$, mainly because chronic

Correspondence to: $\mathrm{Dr} \mathrm{Li}$ Chen, Department of Pathology, Nantong Tumor Hospital, Nantong, P.R. China

E-mail: bl1@ntu.edu.cn

${ }^{*}$ Contributed equally

Key words: dsRNA, TLR3, hepatocellular carcinoma, proliferation, apoptosis hepatitis B carriers account for more than $10 \%$ of the Chinese population (3). The prognosis of patients with $\mathrm{HCC}$ is generally poor, even after surgery or chemotherapy. Liver transplantation (LT) offers a potential curative option for patients with small HCC. However, frequent recurrence or metastasis after transplantation remains the main obstacle for long-term survival (4). Therefore, elucidating the molecular mechanism of $\mathrm{HCC}$ recurrence is vital for the development of more effective therapeutic strategies.

TLR3 recognizes double-stranded RNA, messenger RNA (mRNA), and the synthetic ligand polyinosinic: polycytidylic acid [poly(IC)] $(5,6)$ and is unique among TLRs in that it does not signal through MyD88; rather, it uses a distinct adaptor protein, TRIF (TIR domain-containing adaptor-inducing IFN- $\beta$ ). TLR3 signaling may induce two downstream pathways, the inflammatory or the apoptotic pathway. The inflammatory pathway is mediated mainly by Ripl and leads to NF- $\kappa \mathrm{B}$ activation. The apoptotic pathway, on the other hand, was shown to be mediated by Rip 3 and results in caspase- 8 activation $(7,8)$. We have shown that in human hepatoma cell lines, unlike white blood cells, TLR3 signaling is skewed towards the apoptotic pathway (9). A similar observation was also reported in other tumor cells $(10,11)$ Hepatitis B virus (HBV) and hepatitis $\mathrm{C}$ virus (HCV) induce the type I IFN response, which influences the pathogenesis of chronic viral hepatitis. NS3/4A proteases in HCV disrupt TRIF, thereby blocking TBK1 (12-15) this suggests that the TLR3 pathway plays an important role in the pathogenesis of $\mathrm{HBV}$ and $\mathrm{HCV}$ infections. However, little is known regarding the significance of TLR3 in human carcinoma cells, including hepatocellular carcinoma cells.

In this study, we explored the role of TLR3 in HepG2.2.15 cells by comparing the anti-tumor effects of two TLR3 agonist dsRNA. According to the sequence of TLR3 sensitive virus, double-stranded RNA (dsRNA ), a 23-np (CCGGCCCCUGAAUGCGGCUAAUC) was designed, and termed TLR3 agonist dsRNA (BM-06). We used poly(I:C), a synthetic form of dsRNA, for comparison. We investigated the expression of TLR3 in HCC cells (HepG2.2.15 cells) with secreting HBV by examining the function of the TLR3 signaling protein which occurred after stimulation with BM-06 or poly(I:C) in HepG2.2.15 cells. Our goal is toinvestigate whether activate TLR3 pathway by BM-06 could inhibit the activity of HepG2.2.15 cells. 


\section{Materials and methods}

Cell culture. The human HCC cell line HepG2.2.15 with secreting HBV was purchased from Ruijin Hospital (Shanghai, China). Cells were maintained in Dulbecco's modified Eagle's medium (DMEM) (Gibco BRL, Grand Island, NY, USA) supplemented with $20 \%$ fetal bovine serum (FBS), 2 mM L-glutamine, and $100 \mathrm{U} / \mathrm{ml}$ penicillin-streptomycin mixture (Gibco BRL) at $37^{\circ} \mathrm{C}$ and $5 \% \mathrm{CO}_{2}$ in a humidified chamber.

Dual-luciferase assay for dsRNA activating TLR3. Subcellular fractionation was performed as described by western blot analysis. After treating HepG2.2.15 with BM-06 or poly(I:C), NF- $\kappa B$ activity was checked by dual luciferase reporter gene kit (Promega, USA), which represent the activity of TLR3 in response to dsRNA. Cells were seeded on a 24-well cell culture cluster (Corning Inc., Corning, NY) at a concentration of $5 \times 10^{4} /$ well in a volume of $0.5 \mathrm{ml}$, and grown overnight. pNFкB-TA-luc $(0.8 \mu \mathrm{g})$ (Beyotime Institute of Biotechnology, China) and Renilla reporter plasmids (Promega) were tranfected into cells by Lipofectamine ${ }^{\mathrm{TM}}$ 2000 in 5:1 concentration and replaced for fresh medium after $6 \mathrm{~h}$. The treatment media consisted of DMEM with 20\% FBS and different experimental reagents. All groups were kept in a $37^{\circ} \mathrm{C}$ incubator for $6 \mathrm{~h}$. The medium was removed, and the cells washed with PBS. Cell lysate $(100 \mu \mathrm{l})$ was added in PLB per well at room temperature for $15 \mathrm{~min}$, then the cells were placed in a $1.5 \mathrm{ml}$ microcentrifuge tube. pNFkB-TA-luc and Renilla luciferase activities were evaluated according to the manufacturer's instructions.

Nuclear and cytoplasmic extraction, Western blot analysis. Cells were seeded on a 6-well cell culture cluster (Corning Inc.) at a concentration of $5 \times 10^{4} /$ well in a volume of $2 \mathrm{ml}$, and grown overnight. Cells were treated with $10 \mu \mathrm{g} / \mathrm{ml} \mathrm{BM}-06$ or poly(I:C) or $10 \mu \mathrm{l} \mathrm{PBS}$ as control and incubated for $24 \mathrm{~h}$ at $37^{\circ} \mathrm{C}$. Briefly, cell pellets from a culture were incubated in a hypotonic buffer [10 mM HEPES (pH 7.2), $10 \mathrm{mM} \mathrm{KCl,} 1.5 \mathrm{mM} \mathrm{MgCl}_{2}$, $0.1 \mathrm{mM}$ EDTA, $20 \mathrm{mM} \mathrm{NaF}, 100 \mu \mathrm{M} \mathrm{Na}_{3} \mathrm{VO}_{4}$, and protease inhibitor mixture] for $30 \mathrm{~min}$ at $4^{\circ} \mathrm{C}$ on a rocking platform. Cells were homogenized (Dounce, 30 strokes), and their nuclei were pelleted by centrifugation $\left(10 \mathrm{~min} \times 14,000 \mathrm{rcf}, 4^{\circ} \mathrm{C}\right)$. The supernatant was saved as the cytosolic fraction, and nuclear pellets were incubated in nuclear lysis buffer $[10 \mathrm{~m} \mathrm{M}$ Tris-HCl (pH 7.5), $150 \mathrm{mM} \mathrm{NaCl}, 5 \mathrm{mM}$ EDTA, and 1\% Triton X-100] for $1 \mathrm{~h}$ at $4^{\circ} \mathrm{C}$ on a rocking platform. The nuclear fraction was collected by centrifugation $\left(10 \mathrm{~min} \times 14,000 \mathrm{rcf}, 4^{\circ} \mathrm{C}\right)$.

Prior to immunoblotting, cells were washed twice with icecold PBS, resuspensed in $2 \mathrm{X}$ lysis buffer $(50 \mathrm{mM}$ Tris- $\mathrm{HCl}$, $120 \mathrm{mM} \mathrm{NaCl}, 0.5 \%$ Nonidet P-40, $100 \mathrm{mM} \mathrm{NaF}, 200 \mu \mathrm{M}$ $\mathrm{Na}_{3} \mathrm{VO}_{4}$, and protease inhibitor mixture), and incubated for $20 \mathrm{~min}$ at $4^{\circ} \mathrm{C}$ while rocking. Lysates were cleared by centrifugation $\left(10 \mathrm{~min} \times 12,000 \mathrm{rpm}, 4^{\circ} \mathrm{C}\right)$. Total protein $(50 \mu \mathrm{g})$ were resolved by SDS-PAGE and transferred onto polyvinylidene difuoride membrane filter (Immobilon, Millipore). The membranes were first blocked and then incubated with anti-phospho-NF-кB p65 (Ser 536, 1:500; Cell Signaling Technology, Danvers, MA), anti- $\alpha$-tubulin (sc-8035, 1:100, Santa Cruz Biotechnology, Inc., CA, USA) and anti-lamin B (sc-6217,1:100; Santa Cruz Biotechnology, Inc., CA, USA), antibodies, respectively, for $2 \mathrm{~h}$ at room temperature (RT). After three washes, the membranes were incubated with horseradish peroxidase-conjugated human anti-mouse or antirabbit antibodies (1:1000; Cell Signaling Technology) for $2 \mathrm{~h}$ at RT and developed using a chemiluminescence system (Pierce, Rockford, IL, USA). The film was scanned and the density of the bandsmeasured using ImageQuant software (Molecular Dynamics, Sunnyvale, CA, USA), and then expressed as the percentage of the density of the $\beta$-actin band. In addition, the HepG2.2.15 cells was detected with anti-HBsAg and HBcAg polyclonal antibody (Maixin Biomic, China), respectively.

$q R T-P C R$. Total RNA was isolated from HepG2.2.15 cells using TRIzol (Invitrogen, Carlsbad,CA).qRT-PCR was performed for TLR3, NF- $\kappa B$, HBsAg, HBcAg using an ABI 7700 Sequence Detection Systerm (Applied Biosystems). Cycling conditions for amplification were: $95^{\circ} \mathrm{C}$ for $3 \mathrm{~min} ; 35$ cycles at $95^{\circ} \mathrm{C}$ for $45 \mathrm{sec}, 60^{\circ} \mathrm{C}$ for $45 \mathrm{sec}$, and $72^{\circ} \mathrm{C}$ for $30 \mathrm{sec}$; and finally, $72^{\circ} \mathrm{C}$ for $7 \mathrm{~min}$. The primers are listed in Table I. Each human gene expression was normalized to GAPDH mRNA copies from the same sample.

Cell proliferation assay. Cell proliferation was measured using the CCK-8 assay following the manufacturer's instructions. Briefly, cells were seeded on a 96 -well cell culture cluster (Corning Inc.) at a concentration of $2 \times 10^{4} /$ well in a volume of $100 \mu \mathrm{l}$, and grown overnight. Cell Counting Kit-8 (Dojindo, Kumamoto, Japan) reagents were added to a subset of wells under different treatments, incubated for $2 \mathrm{~h}$ at $37^{\circ} \mathrm{C}$, and absorbance was quantified on an automated plate reader. The experiments were repeated at least three times.

Cell invasion assays. HepG2.2.15 cells $\left(2 \times 10^{4} /\right.$ well) were seeded and incubated in 24 -well at $37^{\circ} \mathrm{C}$ and $5 \% \mathrm{CO}_{2}$ for $24 \mathrm{~h}$. Media consisting of DMEM with 20\% FBS was added for $24 \mathrm{~h}$. Transwell chambers (Corning Inc.) were treated with DMEM for $30 \mathrm{~min}$. Cells were treated with $2.5 \%$ trypsin and suspended in serum-free DMEM medium at a concentration of $1 \times 10^{6} / \mathrm{ml}$. Cell suspension $(200 \mu \mathrm{l})$ was added into each upper chamber and $600 \mu \mathrm{l}$ DMEM medium containing 20\% FBS and $10 \mu \mathrm{g} / \mathrm{ml}$ BM-06 or poly(I:C) or PBS was added into the lower chamber. Then the transwell chambers were incubated in a $37^{\circ} \mathrm{C}, 5 \% \mathrm{CO}_{2}$, humidified incubator for $48 \mathrm{~h}$. The cells on the inner surface of the filter membrane (8.0- $\mu \mathrm{m}$ pore size) were removed. The cells on the lower surface of the membrane were stained with crystal violet, and counted in five random fields under 200 -fold light microscope.

Annexin V-FITC/PI assay. Flow cytometry (Beckman Coulter, Fullerton, CA, USA) was used to determine the apoptotic rate. HepG2.2.15 cells were incubated with BM-06 and poly(I:C) at a concentration of $10 \mu \mathrm{g} / \mathrm{ml}$ for $24 \mathrm{~h}$, harvested, washed with PBS twice, cells were suspended in $500 \mu 1$ binding buffer (BectonDickinson, USA), incubated with $5 \mu 1$ Annexin V- FITC/PI (Becton-Dickinson) and $5 \mu 1$ propidium iodide (PI)(BectonDickinson) for $15 \mathrm{~min}$. Phosphatidyl serine translocation to the cell surface is an indicator of early apoptotic cells; therefore, Annexin V-positive, PI-negative cells were identified as apoptotic. The apoptotic rate was determined using CellQuest software (FCM, Becton-Dickinson). 
Table I. The primers used in the experiments.

\begin{tabular}{lcl}
\hline Number & Name & Sequence $\left(5^{\prime} \rightarrow 3^{\prime}\right)$ \\
\hline Hs-HBV-A1 & F & TGGTTATCGCTGGATGTGTCTG \\
& R & CCGTGCTGGTGGTTGAGG \\
Hs-HBV-B2 & F & TGTGGTTATCCTGCGTTAATG \\
& R & GCGTCAGCAAACACTTGG \\
Hs-NF-kB & F & GTAGTCCCCACGCTGCTCTTCTATA \\
& R & GGAGCAGGCTATCAGTCAGCGC \\
Hs-TLR3 & F & TCCCAGCCTTACAGAGAAGC \\
& R & CCTGTGAGTTCTTGCCCAAT \\
Hs-GAPDH & F & GAAGGTGAAGGTCGGAGTC \\
& R & GAAGATGGTGATGGGATTC \\
\hline
\end{tabular}

Hoechst staining. Cells were seeded onto coverslips in 24-well plates in $20 \%$ FBS-containing medium and then treated with $10 \mu \mathrm{g} / \mathrm{ml}$ BM-06, poly(I:C) and PBS. After removal of culture medium cells were exposed to staining solution containing Hoechst $33258(1 \mu \mathrm{g} / \mathrm{ml})$ (Beyotime Institute of Biotechnology, China) at $37^{\circ} \mathrm{C}$ for $10-30 \mathrm{~min}$. Cells with chromatin condensation were visualized and photographed using a digital fluorescence microscope (Olympus) 30 min after addition of the staining solution. Chromatin condensation is the most characteristic feature of apoptosis. Cell apoptotic ratio was assessed by counting the number of apoptotic cells with condensed nuclei in 6-8 randomly selected areas.

Immunohistochemical staining. HepG2.2.15 cells were incubated with primary antibody (anti-human $\mathrm{HBsAg}$ and $\mathrm{HbcAg}$ polyclonal antibody 1:100 (Maixin Biomic) $30 \mathrm{~min} \mathrm{RT;} \mathrm{at}$ $4^{\circ} \mathrm{C}$ overnight followed by standard avidin-biotin-peroxidase complex technique. Staining was visualized using a $\mathrm{DAB}^{+}$ substrate chromogen solution and hematoxylin QS counterstain. Pictures were taken of five fields of view in each section of the tumor. Representative pictures presenting the experimental results are shown.

Statistical analysis. Statistical analysis was performed using SPSS 17.0 for Windows. The data were expressed as mean \pm SD. Differences between groups were evaluated with ANOVA or factorial design ANOVA and considered statistically significant at $\mathrm{P}<0.05$.

\section{Results}

The effect of activating TLR3 by dsRNA in HepG2.2.15 cells. Since BM-06 or poly(I:C) bound to TLR3 will activate NF- $\kappa$ B and might regulate the nuclear-cytoplasmic shuttling, $\mathrm{NF}-\kappa \mathrm{B}$ activity was checked by qRT-PCR and dual luciferase reporter gene kit after treating HepG2.2.15 with BM-06 or poly(I:C). qRT-PCR showed the expression of TLR3 and NF- $\kappa B$ of
A

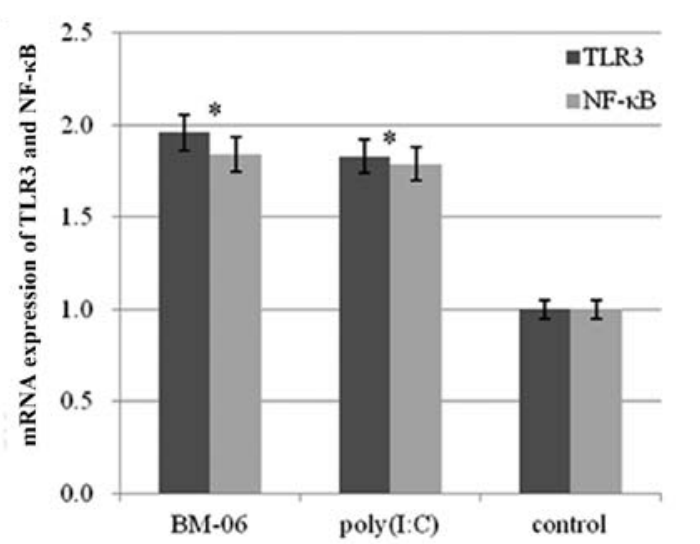

C

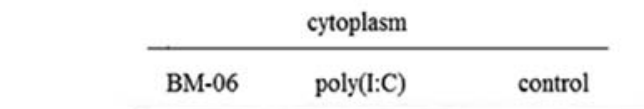

B

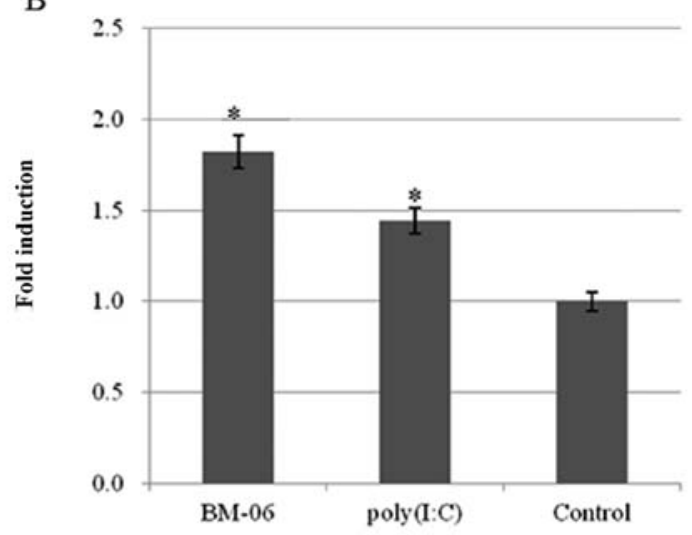

nucleus

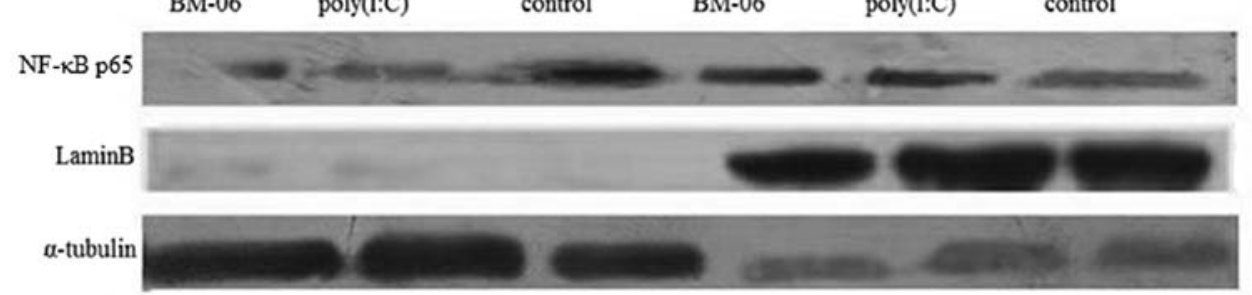

Figure 1. dsRNA activates TLR3. BM-06 showed the best effect in activating TLR3 and NF- $\kappa$ B mRNA. (A) qRT-PCR analysis of the expression of TLR3 and NF- $\mathrm{KB}$ in dsRNA treated HepG2.2.15 cells. (B) Luciferase dual reporter gene test of NF- $\kappa B$ activity of BM-06 and poly(I:C) activating TLR3 $\left({ }^{*} \mathrm{P}<0.05\right.$ vs control group). (C) Western blot analysis of dsRNA induced TLR3-activated HepG2.2.15 cells expressing NF- $\mathrm{KB}$ levels predominating in the cytoplasmic fraction. Cytoplasmic and nuclear fractions were assayed for NF-kB protein ( $\alpha$-tubulin, cytoplasmic marker; lamin B, nuclear marker). 

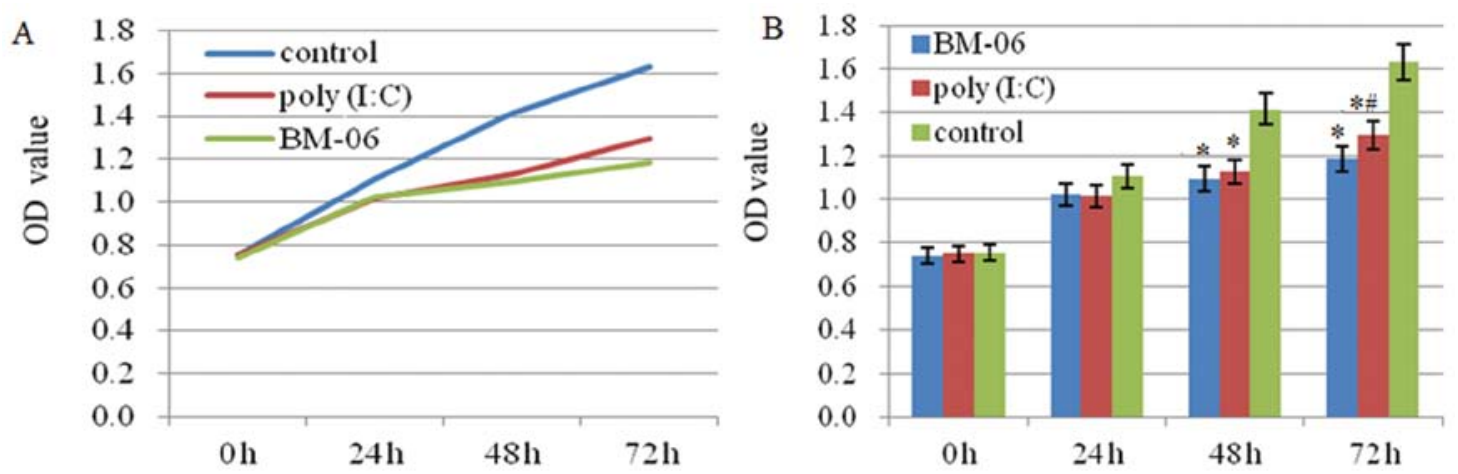

Figure 2. The anti-proliferation of BM-06 in HepG2.2.15 cells. CCK-8 detected cell proliferation at different time-points of each experimental group. Abscissa for the measurement time-points, the vertical axis shows OD values ( ${ }^{*} \mathrm{P}<0.05$ vs control group; ${ }^{\#} \mathrm{P}<0.05$ vs BM- 06 group).
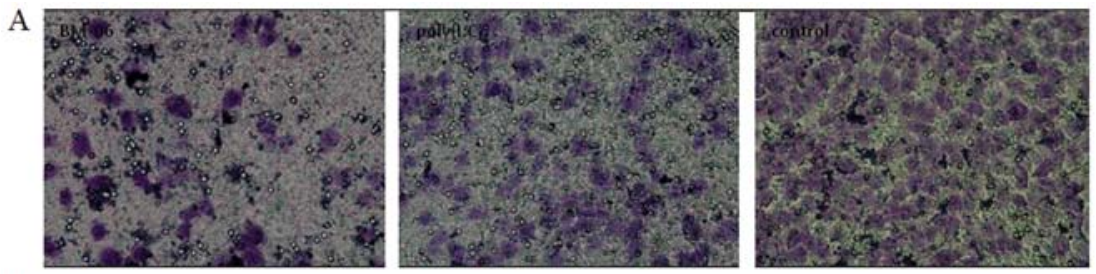

B

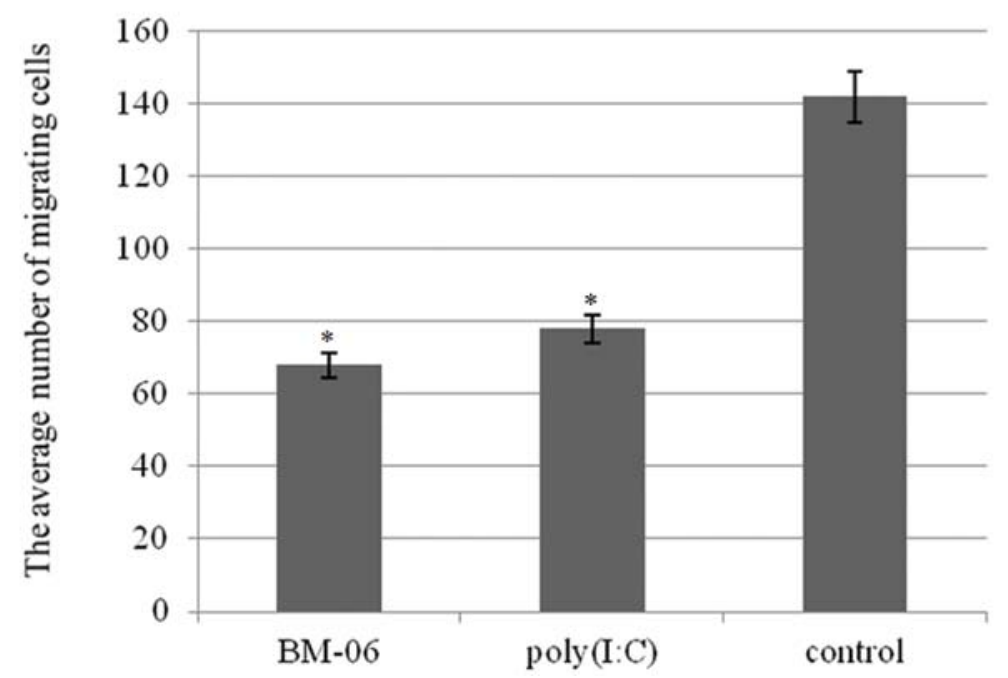

Figure 3. The anti-migration effect of BM-06 in HepG2.2.15 cells. Migration assay of HepG2.2.15 cells stimulated by BM-06 or poly(I:C). Migration was quantified by counting the average number of migrating cells in five different fields in each group (crystal violet staining, $\mathrm{x} 200)$ ("P<0.05 vs control group).

HepG2.2.15 cells was increased (Fig. 1A). Fig. 1B illustrates the effects of the dsRNA on inducing NF- $\mathrm{BB}$. When using $\mathrm{BM}-06$ or poly(I:C), a 1.734 vs. 1.377-fold induction of NF- $\mathrm{KB}$ activity was obtained, respectively, the activation of the NF- $\mathrm{KB}$ indicating the stimulation of TLR3 by BM-06 or poly(I:C). To corroborate these findings, we then tested the expression of endogenous NF- $\mathrm{KB}$ of HepG2.2.15 cells under treatment with BM-06 or poly(I:C). Western blot analysis showed BM-06 or poly(I:C) treated HepG2.2.15 cells which expressed NF- $\mathrm{BB}$ levels predominantly in the nuclear fraction but fewer signals in the cytoplasm (Fig. 1C).

BM-06 inhibiting the proliferation of HepG2.2.15 cells. To examine whether BM-06 affected the proliferation of HepG2.2.15 cells, they were analyzed by a CCK-8 assay performed at different time-points (24, 48 and 72 h) (Fig. 2).
The results showed the proliferative capacity of HepG2.2.15 cells in medium containing BM-06, poly(I:C) were significantly $(\mathrm{P}<0.01 ; \mathrm{P}<0.05)$ lower than that in PBS treated cells. In the BM-06 group, the proliferative capacity was the lowest.

BM-06 inhibiting the invasion of HepG2.2.15 cells. Using chamber precoated with Matrigel, we examined the invasion of HepG2.2.15 cells after treatment with dsRNA. After 48-h incubation, the two treated groups showed significantly decreased invasiveness, compared with the control group (each $\mathrm{P}<0.01)$. Invasiveness through matrigel was significantly decreased in $\mathrm{BM}-06$, compared with poly $(\mathrm{I}: \mathrm{C})$ group $(\mathrm{P}<0.05)$ (Fig. 3).

BM-06 inducing cell apoptosis of HepG2.2.15 cells. Inhibition of cell growth could result from the induction of apoptosis, cell 
A
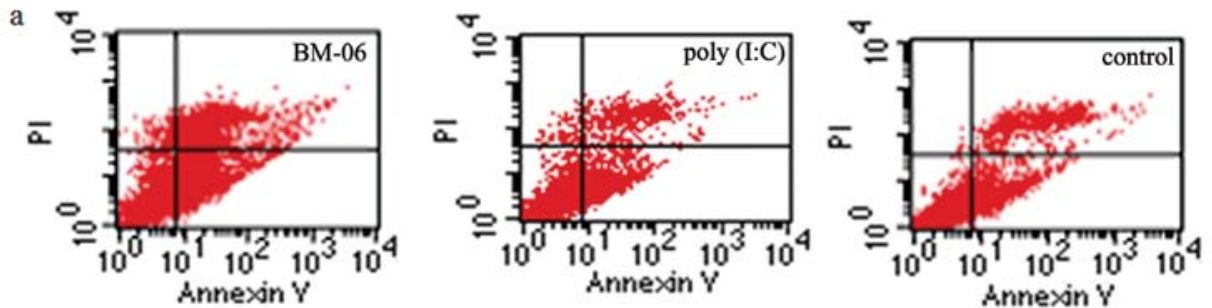

b

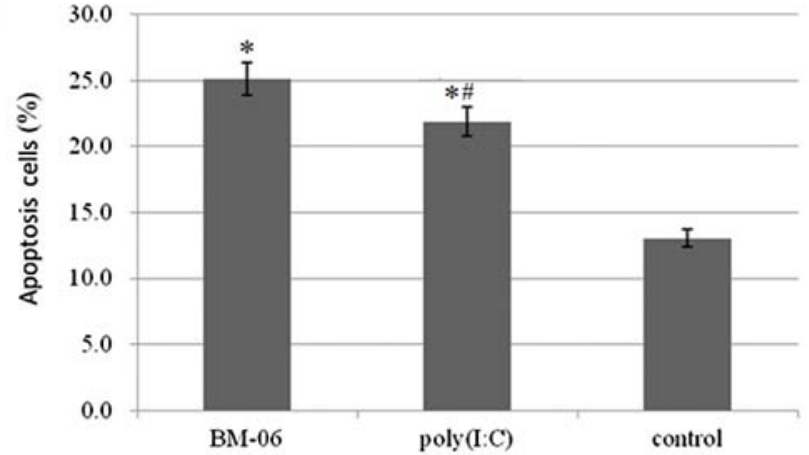

B
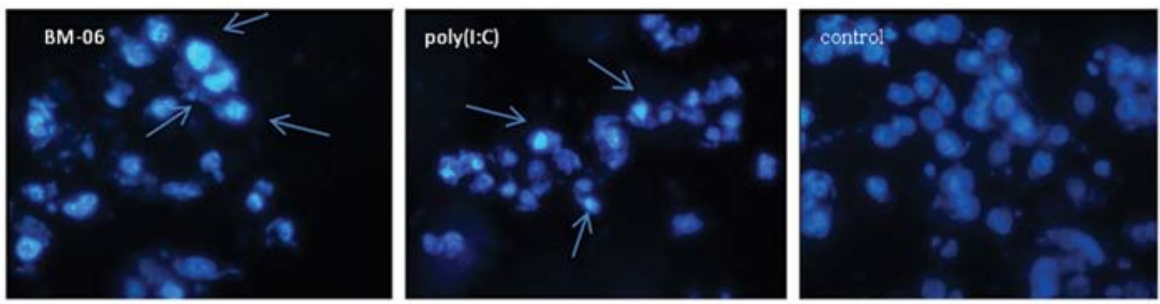

Figure 4. dsRNA induceds HCC cell apoptosis. (A) (a) Flow cytometry detection of apoptosis. (b) Histogram of apoptosis rate of HepG2.2.15 cells of each group ("P<0.05 vs control group; ${ }^{*} \mathrm{P}<0.05$ vs BM-06 group). (B) Hoechst staining (x100).

A

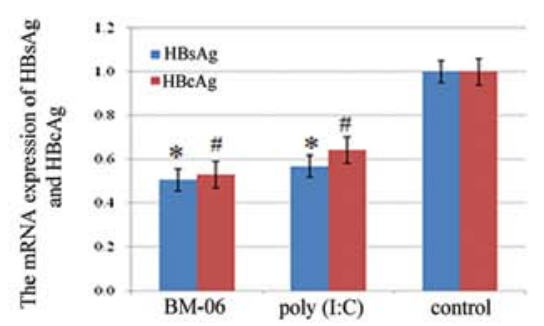

C

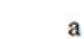

a
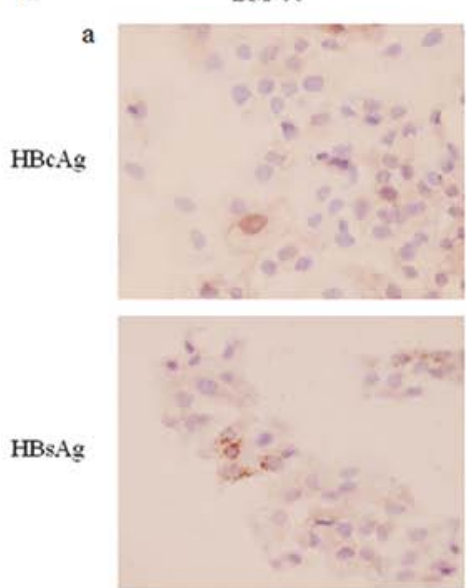

B a

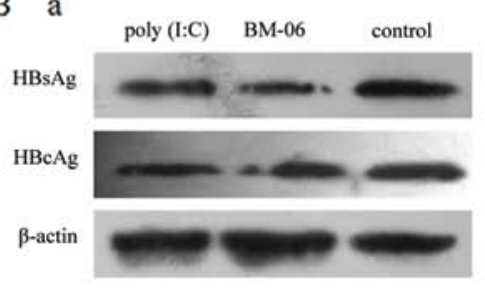

poly(I:C)
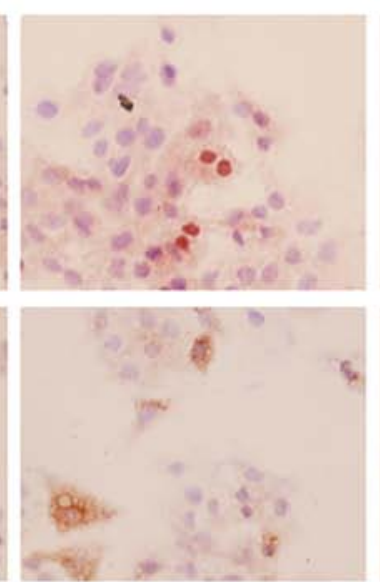

control
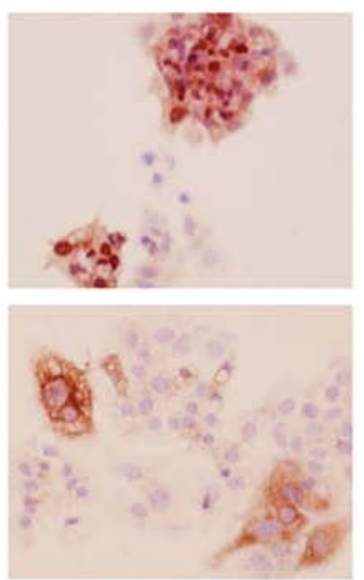

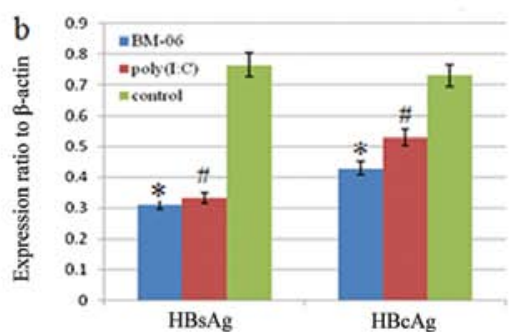

HBsAg

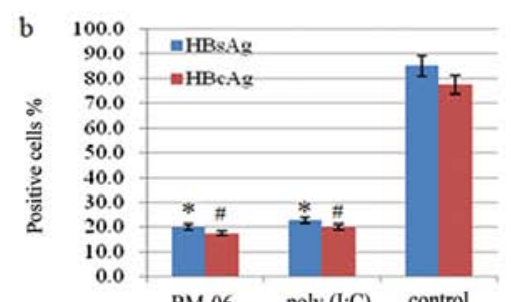

BM-06 poly (I:C) control

Figure 5. dsRNA inhibited the expression of HBsAg and HBcAg in HepG2.2.15 cells. (A) By qRT-PCR. (B) By western blotting. (C) Immunohistochemistry staining (x400) ( $\mathrm{HBsAg}, \mathrm{P}<0.05$ vs control group; ${ }^{*} \mathrm{HBcAg}, \mathrm{P}<0.05$ vs control group). 
growth arrest, and/or the inhibition of growth. We investigated whether activation of the expression of TLR3 and NF- $\kappa$ B induced apoptosis in HepG2.215 cells. The Annexin V-FITC/PI double staining was used as indicator of apoptosis. Activation of TLR3 and NF- $\kappa \mathrm{B}$ increased the percentage of Annexin V-positive/ PI-negative cells (Fig. 4A). We also performed Hoechst nuclear staining in order to determine whether apoptosis occurred. We found that cells treated with BM-06 and poly(I:C) for $24 \mathrm{~h}$ resulted in decreased cell viability and increased cell apoptosis, especially in the BM-06 group. Typical apoptotic features were observed (Fig. 4B).

BM-06 inhibits HBV secretion of HepG2.2.15 cells. TLR3 is generally believed to play an important role in the innate immune response against viral infection, including viral hepatitis infection, although controversial results have been reported (16). The controversial reports on the role of TLR3 in the antiviral defense may be due to the difference in the type of viruses, the type of cells that are infected, the viral load, its model of infection (endoplasmic versus cytoplasmic), and stage of infection. We tested the expression of HBsAg and HBcAg of HepG2.2.15 cells by using qRT-PCR and western blot analysis after treatment with BM-06 or poly(I:C). The results showed that when the cells were treated with dsRNA, the levels of $\mathrm{HBsAg}$ and $\mathrm{HBcAg}$ were greatly reduced (Fig. 5A and B). These results were confirmed by immunohistochemistry stain (Fig. 5C), these results showed that $\mathrm{HBs} \mathrm{Ag}$ and $\mathrm{HBcAg}$ protein was less expressed in dsRNA treated HepG2.2.15 cells.

\section{Discussion}

TLRs are known to be expressed by various immune cells, including dendritic cells, macrophages and lymphocytes, as well as by non-immune cells such as fibroblasts and epithelial cells. Recent studies suggest that dsRNA triggers Toll-like receptor (TLR) signaling via MyD88, leading to the induction of nuclear factor $\kappa \mathrm{B}(\mathrm{NF}-\kappa \mathrm{B})$ and secretion of inflammatory cytokines that in turn prime liver regeneration. TLR3 is unique among TLRs in that it signals through TRIF (TIR domain-containing adaptorinducing interferon- $\beta$ ), not through MyD88, and may lead to activation of either the inflammatory or apoptotic pathway. The inflammatory pathway leads to $\mathrm{NF}-\kappa \mathrm{B}$ activation, whereas the apoptotic pathway, believed to be mediated by Rip3, leads to caspase- 8 activation (17). It is generally believed that TLR3 plays an important role in inhibition of the biological behavior of tumor cells.

Bergé et al (18) found that treatment of HCC mice with poly(I:C), a TLR3 specific ligand, results in suppression of vasculature remodeling and tumor liver growth. They found that liver levels of INF- $\gamma$ were significantly increased in mice treated with dsRNA. INF- $\gamma$ has been identified as an inhibitor of endothelial cell proliferation and a potent suppressor of tumor-associated neovascularization. They demonstrated the INF- $\gamma$ detected in mouse HCC liver extracts was most probably released by circulating or resident immune cells. Recent studies showed that in breast cancer cells, synthetic dsRNA induces apoptosis in a TLR-dependent manner (15). In melanoma cells, TLR3 agonists can directly inhibit cell proliferation and induce tumor cell death (10). Khvalevsky et al (9) found that during the initial phase following partial hepatectomy, TLR3 signaling is induced in hepatocytes, and leads to activation of $\mathrm{NF}-\kappa \mathrm{B}$ as well as increased Rip3 protein levels and caspase- 8 activation. NF- $\kappa \mathrm{B}$ was shown to induce pro-IL-1 $\beta$ expression in hepatocytes, which is then activated by caspase- 8 , leading to inhibition of hepatocyte proliferation. In the present study, we used a 23-np dsRNA (BM-06) to treat HepG2.2.15 cells, and found that BM-06 stimulated TLR3 on the cell surface and activated $\mathrm{NF}-\kappa \mathrm{B}$ and we demonstrated for the first time that activation of TLR3 inhibited the proliferation and invasion, and induced apoptosis in HepG2.2.15 cells. We reasoned that the TLR3-dependent activation of $N F-\kappa B$ and caspase- 8 in hepatocytes could result in an increase in activated IL-1 $\beta$, subsequently inhibiting hepatocyte proliferation and inducing HepG2.2.15 cell apoptosis.

It is generally believed that TLR3 plays an important role in host response to viruses via recognizing dsRNA; however, its role in antiviral immunity has been questioned by some in vivo studies $(19,20)$. The controversial reports on the role of TLR3 in the antiviral defense may be due to the difference in the type of viruses, the type of cells that are infected, the viral load, its model of infection (endoplasmic versus cytoplasmic), and stage of infection. TLR3 plays an important role in host response to viruses via recognizing dsRNA (10). Studies have showed that endogenous RNA released from or associated with necrotic cells also stimulated DCs, leading to interferon- $\alpha$ secretion, which could be abolished by pretreatment of necrotic cells with RNase. These results demonstrate that RNA, likely through secondary structure, is a potent host-derived activator of TLR3 (20). In this study, we found BM-06 can also inhibit the secretion of HBV of HepG2.2.15 cells. TLR3 is generally believed to play an important role in the innate immune response against viral infection, including viral hepatitis infection, although controversial results have been reported (16). The antiviral effects of TLR3 signaling on viral hepatitis infection are likely mediated via stimulating of a variety of cells to produce type I IFN that subsequently inhibits HCV or HBV replication (21-24). These cells include HSCs, monocyte-derived dendritic cells, hepatocytes, Kupffer cells, sinusoidal endothelial cells, and NK cells.

Kleinman et al (25) found, unlike 21- and 23-nucleotide Luc siRNA, 7-, 13-, 16-, or 19-nucleotide versions did not suppress CNV. This, coupled with data that longer duplexes such as $~ 1,000$-nucleotide dsRNA and poly(I:C) suppressed CNV suggest that at least 21 nucleotides are required to activate TLR3. In this study, the length of the dsRNA BM-06 which we designed was 23bp and was able to activate TLR3. We found BM-06 is superior to poly(I:C) in inhibiting the proliferation and promoting apoptosis of HepG2.2.15 cells. These results show that dsRNA stimulation of TLR3 may be sequencespecific.

In conclusion, BM-06 can stimulate functional TLR3 expressed on the HepG2.2.15 cell surface and then activate $\mathrm{NF}-\kappa \mathrm{B}$. BM-06 effectively inhibits the proliferation and invasion of HepG2.2.15 cells in vitro and promotes the apoptosis of HepG2.2.15 cells through the TLR3 pathway. BM-06 can inhibit the secretion of $\mathrm{HBsAg}$ and $\mathrm{HBcAg}$ of HepG2.2.15 cells. In addition BM-06 is superior to poly(I:C) in inhibiting $\mathrm{HCC}$ cells proliferation, promoting apoptosis of $\mathrm{HCC}$ cells and is sequence-specific. Further screening for more effective TLR3 agonist dsRNA, evaluation of the possible roles and the type of regulation associated with TLR3 needs to be undertaken. 


\section{Acknowledgements}

This research was supported by the Foundation of the Ministry of Health, Jiangsu Province, China (no. H201052), the Science Foundation of Nantong City, Jiangsu Province, China (no. K2009060 and S2010018) and the superior subject of Nantong University. The authors gratefully thank Biomics Biotechnologies Co., Ltd. (Nantong, Jiangsu, China) for kindly providing the dsRNA.

\section{References}

1. Bosch FX, Ribes J and Borras J: Epidemiology of primary liver cancer. Semin Liver Dis 19: 271-285, 1999.

2. Kew MC: Epidemiology of hepatocellular carcinoma. Toxicology 181-182: 35-38, 2002

3. Wild CP and Hall AJ: Primary prevention of hepatocellular carcinoma in developing countries. Mutat Res 462: 381-393, 2000.

4. Yoo HY, Patt CH, Geschwind JF and Thuluvath PJ: The outcome of liver transplantation in patients with hepatocellular carcinoma in the United States between 1988 and 2001: 5-year survival has improved significantly with time. J Clin Oncol 21: 4329-4335, 2003.

5. Alexopoulou L, Holt AC, Medzhitov R and Flavell RA: Recognition of double-stranded RNA and activation of NF-kappaB by Toll-like receptor 3. Nature 413: 732-738, 2001.

6. Kariko K, Bhuyan P, Capodici J, Ni H, Lubinski J, Friedman H and Weissman D: Exogenous siRNA mediates sequence-independent gene suppression by signaling through toll-like receptor 3. Cells Tissues Organs 177: 132-138, 2004.

7. Kaiser WJ and Offermann MK: Apoptosis induced by the toll-like receptor adaptor TRIF is dependent on its receptor interacting protein homotypic interaction motif. J Immunol 174: 4942-4952, 2005.

8. Han KJ, Su X, Xu LG, Bin LH, Zhang J and Shu HB: Mechanisms of the TRIF-induced interferon-stimulated response element and NF-kappaB activation and apoptosis pathways. J Biol Chem 279: 15652-15661, 2004.

9. Khvalevsky E, Rivkin L, Rachmilewitz J, Galun E and Giladi H: TLR3 signaling in a hepatoma cell line is skewed towards apoptosis. J Cell Biochem 100: 1301-1312, 2007.

10. Salaun B, Coste I, Rissoan MC, Lebecque SJ and Renno T: TLR3 can directly trigger apoptosis in human cancer cells. J Immunol 176: 4894-4901, 2006.

11. Salaun B, Lebecque S, Matikainen S, Rimoldi D and Romero P: Toll-like receptor 3 expressed by melanoma cells as a target for therapy? Clin Cancer Res 13: 4565-4574, 2006.
12. Li K, Foy E, Ferreon JC, Nakamura M, Ferreon AC, Ikeda M, Ray SC, Gale M Jr and Lemon SM: Immune evasion by hepatitis C virus NS3/4A protease-mediated cleavage of the Toll-like receptor 3 adaptor protein TRIF. Proc Natl Acad Sci USA 102: 2992-2997, 2005.

13. Otsuka M, Kato N, Moriyama M, Taniguchi H, Wang Y, Dharel N, Kawabe T and Omata M: Interaction between the HCV NS3 protein and the host TBK1 protein leads to inhibition of cellular antiviral responses. Hepatology 41: 1004-1012, 2005.

14. Gale M Jr and Foy EM: Evasion of intracellular host defence by hepatitis C virus. Nature 436: 939-945, 2005

15. Ferreon JC, Ferreon AC, Li K and Lemon SM: Molecular determinants of TRIF proteolysis mediated by the hepatitis $\mathrm{C}$ virus NS3/4A protease. J Biol Chem 280: 20483-20492, 2005.

16. Schröder $M$ and Bowie AG: TLR3 in antiviral immunity: key player or bystander? Trends Immunol 26: 462-468, 2005.

17. Zorde-Khvalevsky E, Abramovitch R, Barash H, Spivak-Pohis I, Rivkin L, Rachmilewitz J, Galun E and Giladi H: Toll-like receptor 3 signaling attenuates liver regeneration. Hepatology 50: 198-206, 2009

18. Bergé M, Bonnin P, Sulpice E, Vilar J, Allanic D, Silvestre JS Lévy BI, Tucker GC, Tobelem G and Merkulova-Rainon T: Small interfering RNAs induce target independent inhibition of tumor growth and vasculature remodeling in a mouse model of hepatocellular carcinoma. Am J Pathol 177: 3192-3201, 2010.

19. Vercammen E, Staal J and Beyaert R: Sensing of viral infection and activation of innate immunity by toll-like receptor 3 . Clin Microbiol Rev 21: 13-25, 2008.

20. Karikó K, Ni H, Capodici J, Lamphier M and Weissman D: mRNA is an endogenous ligand for Toll-like receptor 3. J Biol Chem 279: 12542-12550, 2004.

21. Wang B, Trippler M, Pei R, Lu M, Broering R, Gerken G and Schlaak JF: Toll-like receptor activated human and murine hepatic stellate cells are potent regulators of hepatitis $\mathrm{C}$ virus replication. $\mathrm{J}$ Hepatol 51: 1037-1045, 2009.

22. Isogawa M, Robek MD, Furuichi Y and Chisari FV: Toll-like receptor signaling inhibits hepatitis $\mathrm{B}$ virus replication in vivo. $\mathrm{J}$ Virol 79: 7269-7272, 2005.

23. Wu J, Lu M, Meng Z, Trippler M, Broering R, Szczeponek A, Krux F, Dittmer U, Roggendorf M, Gerken G and Schlaak JF: Toll-like receptor-mediated control of HBV replication by nonparenchymal liver cells in mice. Hepatology 46: 1769-1778, 2007.

24. Kanda T, Steele R, Ray R and Ray RB: Hepatitis C virus infection induces the beta interferon signaling pathway in immortalized human hepatocytes. J Virol 81: 12375-12381, 2007.

25. Kleinman ME, Yamada K, Takeda A, et al: Sequence- and targetindependent angiogenesis suppression by siRNA via TLR3. Nature 452: 591-597, 2008. 